\title{
GRAMODENDRINE, A BIPIPERIDYL-INDOLE ALKALOID FROM LUPINUS ARBUSTUS SUBSP. CALCARATUS
}

\author{
William J. KelleR* and George M. HatField ${ }^{\dagger}$
}

*School of Pharmacy, Northeast Louisiana University, Monroe, LA 71209, U.S.A.; †College of Pharmacy, University of Michigan, Ann Arbor, MI 48109, U.S.A.

(Revised received 9 October 1981)

\begin{abstract}
Key Word Index-L Lupinus arbustus subsp. calcaratus; Leguminosae; bipiperidyl-indole alkaloid; gramodendrine (1-acetyl-1, 2, 3, 4-tetrahydro-5-[1-(1-H-indol-3-yl-methyl)-2-piperidinyl]-pyridine).
\end{abstract}

\begin{abstract}
A new bipiperidyl-indole alkaloid, gramodendrine, was isolated from Lupinus arbustus subsp. calcaratus. Its structure was determined from spectral data, degradation to methoxymethylindole and synthesis from ammodendrine.
\end{abstract}

The new alkaloid 1 was isolated from the previously uninvestigated Lupinus arbustus subsp. calcaratus during the course of an investigation dealing with the CNS depressant activity of the alkaloid fraction from this plant. GC-MS analysis of 1 indicated a $\mathrm{M}^{+}$at $m / z$ 208. Of the numerous quinolizidine and piperidine alkaloids isolated from the genus Lupinus, only ammodendrine [1-acetyl-1,2,3,4-tetrahydro-5-(2-piperidinyl)pyridine] has this MW [1-5]. Analysis of this compound indicated that 1 was identical to ammodendrine in GC-MS $R_{t}$ and fragmentation pattern but other chromatographic (TLC) and spectral (NMR, IR) properties were distinctly different for the two compounds. These data suggested thermal decomposition of the new alkaloid to ammodendrine during the course of GC. This was confirmed by prep. GC of 1 followed by TLC of the isolated degradation product, which was found to be identical to ammodendrine.

The principal difference between the 'H NMR spectra of 1 and ammodendrine was the presence of signals due to 8 additional protons in the former. Five were found in the aromatic region $(87.0-7.7)$ and these, together with the broad peak due to an exchangeable proton at $\delta 8.3$, indicated the presence of an indole ring. This was confirmed by the IR spectrum which was remarkably similar to that of ammodendrine except for the presence of a sharp band at $3480 \mathrm{~cm}^{-1}$, which corresponded to an indole $\mathrm{NH}$ absorption. Other notable signals in the ${ }^{1} \mathrm{H}$ NMR spectrum of 1 were those at $\delta 2.1(3 \mathrm{H})$ and $6.6(1 \mathrm{H})$

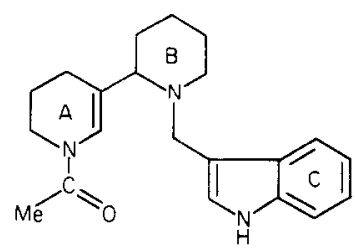

I due to the amide methyl and vinyl protons, respectively, of the ammodendrine moiety. However, unlike the proton spectrum of ammodendrine, the isolated alkaloid lacked a peak due to an exchangeable piperidine $\mathrm{NH}$ proton in the $\delta 1-3$ region. This suggested that the indole containing substituent of 1 was attached to the piperidine nitrogen.

The decoupled ${ }^{13} \mathrm{C}$ NMR spectra of both 1 and ammodendrine exhibited double peaks for numerous carbons due to the presence of both amide conformations. The resulting complexity precluded a complete analysis of these spectra without additional data. However, the spectrum of 1 was consistent with an indole derivative due to the presence of signals in the $\delta 111-136$ region. The rest of the spectrum was similar to that of ammodendrine.

Mass spectral analysis of 1, using both EI and CI with probe temperatures below $150^{\circ}$, established a MW of 337. This indicated that the indole containing substituent attached to the ammodendrine moiety consisted of an indol-3-ylmethyl group. The other major peaks in the EI spectrum $(\mathrm{m} / z 207$ and 130) supported this conclusion since both could arise from cleavage of methylene indole from 1.

The above data suggested that 1 was $N$-(indol3-yl-methyl)-ammodendrine. The proposed structure is an analog of gramine [3-(dimethylaminomethyl) indole], an alkaloid known for its tendency to react with nucleophiles after quaternization of the dimethylamino group [6]. Similar reactivity has been reported for other aminomethylindole containing alkaloids $[7,8]$. The isolated alkaloid exhibited the same sensitivity to nucleophiles and yielded 3-methoxymethylindole (TLC, EI-MS, ${ }^{1} \mathrm{H}$ NMR) when treated with MeI in methanolic $\mathrm{KOH}$. Under these conditions gramine also yields the same product [9]. This reactivity may explain the difficulty encountered in forming a stable salt of 1 . Efforts to form the $\mathrm{HCl}$, $\mathrm{HClO}_{4}$, oxalate and picrate derivatives were all unsuccessful due to the apparent decomposition of the alkaloid. 
The final proof of the proposed structure was obtained by the synthesis of 1 from ammodendrine by way of the Mannich reaction [10]. A yield of over $90 \%$ was obtained and the product was identical to the isolated alkaloid (TLC, ${ }^{1} \mathrm{H}$ and ${ }^{13} \mathrm{C}$ NMR, MS, IR, UV).

The close structural and biosynthetic [11] relationship of 1 to both gramine and ammodendrine led to the name gramodendrine for this novel bipiperidylindole alkaloid. Experiments designed to characterize the pharmacology of gramodendrine are currently in progress.

\section{EXPERIMENTAL}

Plant material. Lupinus abustus Dougl. ex Lindl. subsp. calcaratus (Kell.) Dunn was collected 10 miles east of the Hailey city limits in the Cold Creek region of Blaine County, Idaho, on July 9, 1979. The plant was identified by Dr. David B. Dunn and a voucher specimen (UMO 130847) is on deposit at the University of Missouri Herbarium, Columbia, MO 65201.

Extraction and isolation of gramodendrine (1). The dried, powdered (40 mesh) above ground plant parts $(200 \mathrm{~g})$ were homogenized with EtOH and processed as previously described [12] to give a crude alkaloid fraction. TLC analysis of the extract ( $\mathrm{Si}$ gel, $\mathrm{CHCl}_{3}-\mathrm{MeOH}-18 \mathrm{M} \mathrm{NH}_{4} \mathrm{OH}, 100: 10: 1$ ) revealed the presence of several alkaloids (iodoplatinate reagent). One of these $\left(R_{f} 0.73\right)$ was isolated by prep. TLC (1 mm Si gel PF254) with the above solvent system. The band containing the desired alkaloid was detected under UV light $(254 \mathrm{~nm})$ and was eluted with $\mathrm{MeOH}$. This eluate was taken to dryness and the residue extracted with $\mathrm{CH}_{2} \mathrm{Cl}_{2}$. The latter extract was then subjected to HPLC. The system consisted of a Waters Associates 6000A solvent pump, U6K sample injector, $440 \mathrm{UV}$ detector $(280 \mathrm{~nm})$, and two $3.9 \mathrm{~mm} \times 30 \mathrm{~cm} \mu$ Porasil $^{\mathrm{R}}$ (10 $\mu \mathrm{m}$ silica) columns in series. The solvent, $\mathrm{CH}_{2} \mathrm{Cl}_{2}-\mathrm{MeOH}-18 \mathrm{M} \mathrm{NH}_{4} \mathrm{OH}(275: 10: 1)$, was utilized at a flow rate of $2 \mathrm{ml} / \mathrm{min}$ and the desired alkaloid was eluted in $5 \mathrm{~min}$. Following HPLC, 1 was chromatographically homogeneous in the above TLC and HPLC systems. The isolated alkaloid also gave a single peak $\left(R_{t}=\right.$ $17 \mathrm{~min}$ ) using the following GC-MS system. The column ( $2 \mathrm{~m} \times 2 \mathrm{~mm}$ glass) contained $3 \% \mathrm{OV}-17$ and was eluted with $\mathrm{N}_{2}(30 \mathrm{ml} / \mathrm{min})$ and temp. programmed from $140^{\circ}$ to $265^{\circ}$ at $4 \%$ min. Sample components eluted from the column were detected by EI-MS $(70 \mathrm{eV})$. Under these conditions the isolated alkaloid gave a mass spectrum identical to ammodendrine [13].

The alkaloid was obtained as an amorphous solid and attempts to prepare a crystalline salt were unsuccessful. The yield of gramodendrine from the above isolation scheme was $28 \mathrm{mg}$. However, quantitative analysis (TLC) indicated that the dried plant material contained $0.02 \%$ of this alkaloid.

Gramodendrine (1). UV $\lambda_{\max }^{\mathrm{MeOH}} \mathrm{nm}(\log \epsilon): 217$ (4.55) and 248 (4.24). IR $\nu_{\max }^{\mathrm{CHCl}_{3}} \mathrm{~cm}^{-1}: 3480(\mathrm{NH}), 2940,1630(\mathrm{C}=0), 1415$, $1350,1260,1180,1085$ and 985 . El-MS (direct inlet, probe below $150^{\circ}$ ) $70 \mathrm{eV}, \mathrm{m} / z$ (rel. int.): $337[\mathrm{M}]^{+}(30), 207[\mathrm{M}-$ $130]^{+}(40), 165\left[\mathrm{M}-130-\mathrm{COCH}_{3}\right]^{+}(20)$, and $130[\mathrm{M}-207]^{+}$ (100). CI-MS (direct inlet, probe below $150^{\circ}$ ) methane, $\mathrm{m} / \mathrm{z}$ (rel, int.): $338[\mathrm{MH}]^{+}(20), 209$ [protonated ammodendrine from thermal decomposition of 1$]^{+}(100)$, and 130 [MH $208]^{+}$(38). ${ }^{1} \mathrm{H}$ NMR $\left(360 \mathrm{MHz}, \mathrm{CDCl}_{3}\right): 1.11 \mathrm{~m}, 1.44 \mathrm{~m}$, $1.75 m$ and $2.55 m\left(10 \mathrm{H}, \mathrm{H}_{2}-3 \mathrm{~A}, \mathrm{H}_{2}-4 \mathrm{~A}, \mathrm{H}_{2}-3 \mathrm{~B}, \mathrm{H}_{2}-4 \mathrm{~B}\right.$ and $\left.\mathrm{H}_{2}-5 \mathrm{~B}\right), 2.07$ and $2.08(3 \mathrm{H}, s$ split by amide conformations, $\left.\mathrm{COCH}_{3}\right), 2.15(1 \mathrm{H}, m, \mathrm{H}-6 \mathrm{~B}$ axial $), 2.35(\mathrm{H}, m, \mathrm{H}-6 \mathrm{~B}$ equa- torial), $2.95(1 \mathrm{H}, m, \mathrm{H}-2 \mathrm{~B}), 3.10(1 \mathrm{H}, d, J=13 \mathrm{~Hz}$, indol-3-yl $-\mathrm{CH}-\mathrm{N}), 3.40(1 \mathrm{H}, \mathrm{m}, \mathrm{H}-2 \mathrm{~A}$, axial), $3.55 \mathrm{~m}$ and $3.80 \mathrm{~m}(1 \mathrm{H}$, split by amide conformations, H-2A, equatorial), $3.95(1 \mathrm{H}$, $d, J=13 \mathrm{~Hz}$, indol-3-yl-CH-N), 6.60 and $7.27(1 \mathrm{H}, s$ split by amide conformations, $\mathrm{H}-6 \mathrm{~A}), 7.10(3 \mathrm{H}, m, \mathrm{H}-2 \mathrm{C}, \mathrm{H}-5 \mathrm{C}$ and $\mathrm{H}-6 \mathrm{C}), 7.25(1 \mathrm{H}, d, J=7 \mathrm{~Hz}, \mathrm{H}-7 \mathrm{C}), 7.65(1 \mathrm{H}, d$, $J=7 \mathrm{~Hz}, \mathrm{H}-4 \mathrm{C}), 8.30(1 \mathrm{H}, s, \mathrm{NH})$. Interpretation was aided by decoupling, comparison with the spectrum of ammodendrine [14] and related compounds $[7,8]$, and prepn of the indol-3-yl- $\mathrm{CD}_{2}-\mathrm{N}$ derivative of 1 . The deuterated derivative was prepared as described below using deuterated paraformaldehyde and lacked the doublets at $\delta 3.10$ and 3.95 observed in the spectrum of $1 .{ }^{13} \mathrm{C} \mathrm{NMR}\left(22.63 \mathrm{MHz}, \mathrm{CDCl}_{3}\right.$, off resonance multiplicity where possible to interpret): 21.0 , $21.5,21.8,22.2,24.8 t, 25.9 t, 32.2 t$ and $32.6 t(\mathrm{C}-3 \mathrm{~A}, \mathrm{C}-4 \mathrm{~A}$, $\mathrm{C}-3 \mathrm{~B}, \mathrm{C}-4 \mathrm{~B}, \mathrm{C}-5 \mathrm{~B}$ and $\left.\mathrm{CH}_{3}\right) 40.8 t$ and $44.8 t(\mathrm{C}-2 \mathrm{~A})$, $50.6 t$ and $50.9 t$ (indol-3-yl-C-N), $52.9 t$ and $53.2 t$ (C-6B), $68.3 d$ and $68.9 d(\mathrm{C}-2 \mathrm{~B}), 111.0(d, \mathrm{C}-7 \mathrm{C}), 119.1,119.6,120.9$, $121.7,122.5,123.4,123.6,124.1$ (C-5A, C-6A, C-2C, C-3C, C-4C, C-5C and C-6C), $127.6(s, C-3 . \mathrm{C}), 136.4(s, C-7 \mathrm{C})$, $168.0(s, \mathrm{C}=\mathrm{O})$ [15]. The doubling of some signals is due to the presence of two amide conformations.

Degradation of 1 to 3 -methorymethylindole. 1 (15.8 $\mathrm{mg}$ ) was dissolved in $1 \mathrm{ml}$ of $\mathrm{MeOH}$ and treated with methyl iodide $(50 \mu \mathrm{l})$ and $25 \%$ methanolic $\mathrm{KOH}(50 \mu \mathrm{l})$ as reported previously for the degradation of gramine [9]. The reaction mixture was then evapd to dryness and the residue extracted with ether. The residue from this extraction was subjected to column $(1.5 \mathrm{~cm} \times 20 \mathrm{~cm})$ chromatography using $\mathrm{Si}$ gel and $\mathrm{CH}_{2} \mathrm{Cl}_{2}-\mathrm{MeOH}(20: 1)$. The methoxymethylindole fraction was further purified by HPLC, as previously described, using a $3.9 \mathrm{~mm} \times 30 \mathrm{~cm} \mu$ Porasil $^{\mathrm{R}}$ column with ethyl acetate- $n$-hexane $(5: 1)$ at $5 \mathrm{ml} / \mathrm{min}$. The yield of chromatographically pure methoxymethylindole was $2.3 \mathrm{mg}$. ' $\mathrm{H}$ NMR $\left(360 \mathrm{MHz}\right.$, acetone- $\left.d_{6}\right): 3.3\left(3 \mathrm{H}, s, \mathrm{CH}_{3}\right), 4.6\left(2 \mathrm{H}, s, \mathrm{CH}_{2}\right)$, $7.05 t, J=8.5 \mathrm{~Hz}$ and $7.10 t, J=8.5 \mathrm{~Hz}(2 \mathrm{H}, \mathrm{H}-5$ and $\mathrm{H}-6)$, $7.30(1 \mathrm{H}, s, \mathrm{H}-2), 7.39(1 \mathrm{H}, d, J=8.5 \mathrm{~Hz}, \mathrm{H}-7)$, and $7.62(1 \mathrm{H}$, $d, J=8.5 \mathrm{~Hz}, \mathrm{H}-4)$. GC-MS $70 \mathrm{eV}, m / z$ (rel. int.): $130[\mathrm{M}-$ $\left.\mathrm{OCH}_{3}\right]^{+}(100), 103\left[\mathrm{M}-\mathrm{OCH}_{3}-\mathrm{HCN}\right]^{+}(12), 77\left[\mathrm{M}-\mathrm{OCH}_{3}-\right.$ $\mathrm{HCN}-\mathrm{HC}=\mathrm{CH}]^{+}(20)[16]$. These spectral properties were identical to those of methoxymethylindole prepared from gramine.

Synthesis of gramodendreine. Ammodendrine perchlorate $(30 \mathrm{mg})$ and indole $(11.3 \mathrm{mg})$ were dissolved in $0.5 \mathrm{ml} \mathrm{EtOH}$ with the aid of heat. Formalin $(30 \mu \mathrm{l})$ was added after cooling to room temp. and the reaction mixture was heated at $50^{\circ}$ for $16 \mathrm{hr}$. The solvent was then removed and the residue subjected to column $(1.5 \mathrm{~cm} \times 25 \mathrm{~cm})$ chromatography using $\mathrm{Si}$ gel and $\mathrm{CH}_{2} \mathrm{Cl}_{2}-\mathrm{MeOH}-18 \mathrm{M} \quad \mathrm{NH}_{4} \mathrm{OH}$ (100:10:1). A chromatographically homogeneous (TLC) fraction contained $30 \mathrm{mg}$ of 1 (yield $92 \%$ ). This material was identical to the plant derived alkaloid (TLC, HPLC, ${ }^{1} \mathrm{H}$ and ${ }^{13} \mathrm{C}$ NMR, IR and EI-MS).

Acknowledgements-This research was supported, in part, by a grant from the North-East Louisiana University Faculty Research Fund. The authors wish to acknowledge the efforts of Cheryl B. Keller, who collected the plant material, and Dr. David B. Dunn (University of Missouri) who identified it. We also wish to thank James G. Omichinski for his laboratory assistance and Dr. Carl Djerassi for a sample of ammodendrine

\section{REFERENCES}

1. Willaman, J. J. and Schubert, B. G. (1961) Alkaloid Bearing Plants and Their Contained Alkaloids, pp. 116- 
119. Agricultural Research Service, U.S.D.A., Technical Bulletin, 1234, Washington, D.C.

2. Willaman, J. J. and Li, H.-L. (1970) Lloydia 33, 110.

3. Mears, J. A. and Mabry, T. J. (1971) in Chemotaxonomy of the Leguminosae (Harborne, J. B., Boulter, D. and Turner, B. L. eds.) p. 73. Academic Press, London.

4. Raffauf, R. F. (1970) A Handbook of Alkaloids and Alkaloid-Containing Plants. Wiley-Interscience, New York.

5. Kinghorn, A. D., Selim, M. A. and Smolenski, S. J. (1980) Phytochemistry 19, 1705.

6. Marion, L. (1952) in The Alkaloids-Chemistry and Physiology, Vol. II (Manske, R. H. F. and Holmes, H. L. eds.) p. 373. Academic Press, New York.

7. Walser, A. and Djerassi, C. (1964) Helv. Chim. Acta 47, 2072.

8. Joule, J. A., Monteiro, H., Durham, L. J., Gilbert, B., and Djerassi, C. (1965) J. Chem. Soc. 4773.
9. Madinaveitia, J. (1937) J. Chem. Soc. 1927.

10. Kuhn, H. and Stein. O. (1937) Chem. Ber. 70, 567.

11. Saxton, J. E. (1965) in The Alkaloids-Chemistry and Physiology, Vol. VIII. (Manske, R. H. F. ed.) p. 6. Academic Press, New York.

12. Keller, W. J. and Zelenski, S. G. (1978) J. Pharm. Sci. $67,430$.

13. Arndt, R. R. and DuPlessis, L. M. (1968) J. S. Afr. Chem. Inst. 21, 54.

14. Fitch, W. L., Dolinger, P. M. and Djerassi, C. (1974) J. Org. Chem. 39, 2974.

15. Shamma, M. and Hindenlang, D. M. (1979) Carbon-13 NMR Shift Assignments of Amines and Alkaloids, 303 pp. Plenum, New York.

16. Budzikiewicz, H., Djerassi, C., and Williams, D. H. (1967) Mass Spectroscopy of Organic Compounds, p. 610. Holden-Day, San Francisco. 